\title{
A Perspective of the Implications of the Common European Framework Implementation in the Colombian Socio-cultural Context
}

Jair Ayala Zárate* José Aldemar Álvarez V. **

\begin{abstract}
English language teaching around the world is taking new routes at an accelerated rhythm. As part of a globalized world, Colombia has been trying to accommodate to the new dynamics. One way to do this is through the de-contextualized implementation of standards adapted and/or adopted from overseas. This article aims at promoting reflection and awareness on implications that might arise due to the implementation of the Common European Framework (CEF) in Colombia. This paper bases its discussion on relevant literature related to bilingualism, the CEF and the Colombian Ministry of Education. The conclusion states the need for the construction of standards regarding foreign language education based on our contextual features, not leaving aside the issue of being globally competent.
\end{abstract}

Key words: Standards for foreing Language, Common European Framework (CEF), Language polices bilingualism, Ministry of National Education, Colombia.

\section{Resumen}

La enseñanza del Inglés en todo el mundo está tomando nuevos caminos a un ritmo acelerado. Como parte de la globalización mundial, Colombia ha estado tratando de acomodarse a las nuevas dinámicas en la enseñanza de idiomas. Una forma de hacer esto es a través de la implementación descontextualizada de estándares de modelos de enseñanza-aprendizaje adaptados o adoptados de otros países. Este artículo pretende promover la reflexión y crear conciencia acerca de las muchas implicaciones que pueden surgir debido a la implementación del Marco de Referencia Europeo en nuestro contexto. Este documento fundamenta su tesis en bibliografía relacionada con el bilingüismo, el MRE (Marco de Referencia Europeo) y el MEN (Ministerio de Educación Nacional de Colombia). Las conclusiones muestran la necesidad de crear unos estándares para la educación en lenguas extranjeras teniendo en cuenta nuestras características contextuales, sin dejar de lado el hecho de ser globalmente competentes.

Palabras claves: estándares para lengua extranjera, MFE (Marco de Referencia Europeo), políticas lingüísticas bilingüismo, MEN (Ministerio de Educación Nacional Colombiano).

* Received: 30-03-05 / Accepted: 23-05-005

1 This paper was presented by the authors at the 39th National ASOCOPI Conference on Defining standards in ELT. October 2004. 


\section{Introduction}

Standards in foreign language education have constituted a matter of concern since at this time the Ministry of Education has not proposed any standards for foreign language teaching-learning processes in our country (although standards in subjects such as math, science and others have already been issued). Due to the lack of contextualized criteria that take into account our specific socio-cultural characteristics and needs; attention has now turned to the adoption or adaptation of standards for foreign language education such as the Common European Framework (CEF).

Being the foreign language education in Colombia the core of this discussion, it is necessary to bear in mind characteristics and needs of this country. The characteristics that are discussed along this paper are the issues related to the geographical location, the students and teachers population; and the educational system as well as the educational policies of the Colombian context.

By the same token, there are some needs that are paramount when dealing with foreign language teaching-learning process. For example, first, there is the need to improve teacher professional development programs and educational institutions facilities. Second, there is the need to develop FL standards and a curriculum that match not only the students' needs, but also the teachers' possibilities to fulfill those needs. And third, FL education needs to include research as a relevant component in the Colombian educational agenda. In sum, the characteristics and the needs of FL teaching and learning practice in Colombia, addressed in this document, have to do with socio-cultural, economical and political dimensions.

In order to account for the issues above mentioned this paper focuses on answering the following questions:

- What are the implications that might arise from the implementation of the CEF in our Colombian educational context?

- What should be considered in order to set up standards for foreign language teaching-learning in Colombia?

This article consists of four major parts, in the first part; we define standards and see them at the light of the Colombian Foreign Language educational policies. In the second one, we present the theoretical and conceptual grounds 
of the Common European Framework. In the third part, we mention the possible implication that may arise when implementing the CEF in our socio-cultural Colombian context. Finally, we try to outline some actions to take in regards to the adoption and/or adaptation of international standards related to foreign language teaching.

\section{A view on standards}

In order to define a standard, it should be kept in mind that it is a marketing concept. It was intended to be a way to define common product characteristics to satisfy customers' needs (OTI, 2004). Afterwards, this concept was used in other professional fields to achieve certain parameters and to measure product quality. Therefore, some institutions that set standards appeared. Internationally there is the International Standard Organization (ISO) and at a local level the Instituto Colombiano de Normas Técnicas y Certificación (ICONTEC). The concept has expanded into education and nowadays standards are being established for language teaching to set global criteria in order to know what teachers should teach, how they should teach, and what students should know at a certain level and at a certain period of time.

According to UNESCO (2004), standards are theoretical constructs used as a criterion or set of criteria to take any action. They are recognized as valid, valuable, and reliable by a community. Thus, in education, it is the academic community which has to validate those parameters or criteria that measure how qualified or proficient a person (teacher or learner) is in a language.

\section{Standards in Colombia}

In Colombia the MEN (Ministry of National Education) is the entity that sets the teaching-learning standards. It states that standards should be clear and serve as public criteria for Colombians to know what is to be learned, and they are the point of reference for the learner to know what he/she is able to learn and able to do with what he/she knows. These standards are intended to be implemented in all urban or rural, public or private schools of the country in order to have the same quality in education (Ministry of National Education, 1999).

Implementing standards in urban or rural, public or private schools of the country brings up some things to consider. For instance, this proposal does 
not seem to account for the differences that separate urban and rural as well as public and private education. It is undeniable that these contexts differ in logistics, student population needs and teachers' training.

In regards to logistics, the budget is the principal issue to mention since it determines the funds for school facilities and for sources of information. To exemplify this, private schools are funded independently; they are not subject to the limitations of state education budgets and have more freedom to invest in new technologies and materials. Opposite to that, public schools must follow all state and local laws in education. Such laws usually include specifics about funding for the educational system ${ }^{2}$. Besides, the budget assigned by the Government to public institutions is not enough to invest in instructional resources-books, posters, laboratory equipment-; and in facilities improvementlibraries, computer rooms and so forth.

Our experience, as learners and as teachers of languages, in different contexts and populations, has shown that private school student population lives under a different realia to public school student population. In general, private school families are wealthier than public school families. Parents of private school students provide their children with the necessary supplies for their school work. Public school students do not usually have the basic supplies like, notebooks, pencils or access to different sources of information etc. It is even common to see students that have to work in order to help their families with their house expenses. Then, what priority can a child give to studying when there are other concerns that seem to be primary for him/her and his/her family?. For these and some other reasons, private school students do not live the same reality and do not have similar needs to public school students.

Public school teachers also differ from private school teachers. One main difference is the professional training teachers receive. Specially, in reference to foreign language education, private school teachers often have subject area expertise and an undergraduate or graduate degree in the subject they teach. In addition, they are offered more training and methodological updating, for example publishing houses train teachers on how to use textbooks as part of the teaching methodology, On the other hand, in public education teachers

2 These laws also include regulations about program and curriculum development different to private schools regulations which are freer in its curriculum design. 
from different subject matters such as social education, literature and others usually have to teach for instance the subject of English without previous training. Although some changes have been introduced during the last years ${ }^{3}$, teachers with professional formation in the teaching of languages still lack to receive more of professional development training.

Differences stated above about logistics, student population needs and teachers' training evidence the divergence of public and private school contexts. As concluded in a research carried out by Gonzales and Quinchía (2003) with public school teachers, the two settings (private and public schools) need to be considered as two separate worlds. To illustrate this, the authors found that teachers think school students differ in social class and standard of living ${ }^{4}$, also that their work conditions are very different. For example, Nancy, a participant of this research, asserts that public schools have large classes and many students, whereas private schools have small classes. Therefore, it is difficult to say to what extent urban or rural and public or private schools could have the same standards to achieve equal goals, considering that their needs and contexts are different.

Although the Ministry of Education has set up standards for all the other subjects taught in Colombian schools, there are no clear standards for foreign language teaching and learning. The document "Lineamientos Curriculares del área de Lenguas Extranjeras" (general guidelines for the teaching of foreign languages) published by the MEN in 1999 sets some general standards as it states: "The standards included in these pages are generic, and are not written

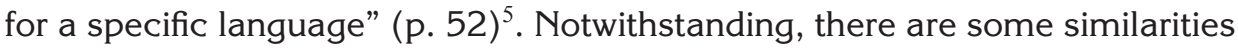
in the processes that support the teaching-learning of a foreign language. It is necessary to consider that socio-cultural dimensions vary with different languages. Learning English is not the same as learning French or German.

3 Nowadays the Government is investing more in public school teachers' education. For example, the Ministry of National Education has implemented teacher development programs (TDP) for teachers of English as a way to widen their professional knowledge.

4 "The possibilities for teachers in private schools are different. Private school students go easily to the United States once a year... they have cable TV with thirty, fifty channels... their parents are professionals that speak English" p. 93.

5 Translation by the authors. 


\section{The same document asserts:}

"The standards for foreign languages are proposed taking into account many audiences and with several implicit purposes. They do not describe the state of the art of education in foreign languages in our country... They are not a curricular guide... they do not describe the specific contents of a program, neither a unique perspective..." (p. 52) ${ }^{6}$

From the quote, we can infer that standards do not come from a consideration of the state of current pedagogical processes regarding foreign languages in our country. The idea of setting standards without understanding what the students, teachers, and institutions need to carry out their tasks blurs the scope, reliability and validity of the proposal. We consider that if we are to propose standards, they should be based on a Colombian context, informed perspectives and methodologies. They shouldn't be an eclectic mixture because the role of standards is to guide a process.

Because Colombian standards for foreign language teaching are barely structured, attention has been given to foreign models. In general, standards have been obtained by importing the ones that were developed in other places, under different circumstances and contexts. Although those standards are valid and reliable for foreign academic communities, it does not mean that they would fit the particularities of our institutions, language learners, and so forth.

Imported standards not only deal with language policies of foreign countries but also with foreign curricula, syllabi, teaching-learning methodologies, testing, assessment, evaluation, and instructional materials. They usually come from educational systems belonging to North America or Europe. Sometimes these standards are adapted or adopted ${ }^{7}$ because of their popularity or achievements in another context. This is the case of the Common European Framework, which has been proposed to integrate language-teaching policies in Europe and is currently being implemented by some private institutions in Bogotá. Next, we describe the basis of the CEF and some of the principles that support what it proposes.

6 Translation by the authors.

7 These two terms are used to mean two different actions: "adapted" refers to the issue of making suitable or fitting something for a specific situation under new conditions. "Adopted" on the other hand, refers to assume an idea and practice it as one's own. Webster's New World (1997) 


\section{The Common European Framework: an overview}

The CEF was developed through extensive research and consultation around Europe. It is based on an intercultural language teaching-learning approach that sets standards for language learning, teaching and assessment and in this regard

“... provides a common basis for the elaboration of language syllabuses, curriculum guidelines, examinations, textbooks, etc. across Europe. It describes in a comprehensive way what learners have to learn to do in order to use a language for communication and what knowledge and skills they have to develop so as to be able to act effectively." (CEF, 2001 p. 1)

The CEF was proposed as part of the overall language policy of the Council of Europe, ${ }^{8}$ whose aims are to:

a. Protect and develop the heritage of diverse languages and cultures in Europe.

b. Facilitate communication and interaction among Europeans to promote European mobility, mutual understanding, and cooperation in order to overcome prejudice and discrimination.

c. Achieve convergence at the European level regarding modern language teaching and learning policies.

\section{Some basic constructs}

The CEF is designed to achieve political, cultural, academic, and economical objectives. It is necessary to consider that it was elaborated to suit specific needs and characteristics that were identified in the European context. The most relevant characteristics are ethnic richness, language variety and the geographical conditions encountered on the continent that make it a multicultural and multilingual society. The CEF has been developed using a

8 The Council of Europe is an organization that aims at achieving greater unity among its members; more than 45 European nations belong to it. 
pluri-cultural approach that differs from a multi-cultural approach in that the cultures do not only co-exist side-by-side but are compared, contrasted and actively combined to produce an enriched and integrated culture competence (CEF, 2001).

At the same time, the Framework has gone beyond the concept of bilingualism as asserted by Hammers \& Blanc (2000) who define bilingualism as the state of a linguistic community in which two languages are in contact with the result that codes can be used in the same interaction. In the same way, the CEF has not opted for a multilingual approach. Conversely, it has adopted a plurilingual approach. The former emphasizes the fact that the individual's personal experience expands and builds up a communicative competence to which all knowledge and experience of languages contribute, relate and interact. The latter has to do with the knowledge of a number of languages that merely co-exist in a society.

The pluricultural and plurilingual approach undertaken by the CEF shows that the Council of Europe intends to promote an enriched ${ }^{9}$ language educational model that looks for an additive ${ }^{10}$ type of outcome in the language learner. However, it is still unclear as to the type of bilingual program, immersion, submersion, maintenance, ESL pullout -language shelter, transitional, enrichment -two-way, heritage language programs, dual-language programs, developmental bilingual that will be adopted by the different countries that are implementing the CEF (See Roberts 1995, Freeman 1998, Romaine, 2001). A bilingual or plurilingual process as explained by Romaine (2001) has to be coherent regarding the educational model chosen, the program to carry it out and the kind of bilingual outcome aimed at.

On the whole, the CEF is based on a systematic and rigorous process that proposes a set of criteria for language teaching and teaching-learning across Europe. The framework intends to be open and flexible. "We have NOT set out to tell practitioners what to do or how to do it." (p xi). However, it is

9 “...encompasses all those bilingual educational programs that encourage the development of minority languages at the individual and collective levels, cultural pluralism at school and in the community, and an integrated national society based on the autonomy of cultural groups. Hornberger, 1991: 22; as cited by Freeman,1998)

10 Refers to the form of bilingualism that results when students add a second or more languages to their native language (Lambert, 1975; as cited by Roberts,1995) 
undeniable that the establishment of the common levels of proficiency and descriptors ${ }^{11}$, to be achieved by learners and teachers, demand or imply certain approaches, method and techniques in as much as "... from one point of view setting standards is rather like 'making rules"” (Van Avermaet, 2004) ${ }^{12}$.

Additionally, the CEF asserts that its use is subject to the specific needs, objectives, concerns, motivations, characteristics of specific contexts, teachers, and learners. The controversy does not lie on the issue of implementing it or not, but in the way it is being adapted or adopted in Colombia. The following section aims at answering the first of the two questions that are at the core of this article. It deals with some considerations concerning the impact of the implementation of the Common European Framework in our context.

\section{Implementing a foreign model: some considerations}

After revising some of the principal constructs introductory to our discussion, and some issues about the state of the art concerning foreign language education in Colombia, we focus now on the implications of implementing international standards and, more particularly, the CEF in Colombia.

\section{Socio-political and economical issues}

The adoption of any educational model or program such as the CEF raises many questions in regards to its implementation. International standards do not fulfill specific needs of special conditions such as ours. The Ministry of Education (1999) states that there are particularities that create a gap between the developed countries and the developing ones regarding economical, political, and educational policies. Not all Colombian schools have the same physical resources (laboratories, libraries, and other instructional materials), technology, human resources (a properly trained number of language teachers) and enough governmental economical investment -as argued previously in this paper.

11 It is contradictory to say that standards are not being set when common levels of proficiency and descriptors are established for somebody to achieve in order to belong to a "community" that will be measured by the same criteria.

12 Taken from the section Quality of Assurance at the ALTE (Association of Language Testers in Europe web page). 
This is shown by the findings of a research project that is being carried out in the metropolitan area of Medellín. The project involves teachers from seven public schools (Cadavid, McNulty \& Quinchía, 2004). According to the researchers, teachers lack an adequate proficiency in English, background knowledge of the subject matter and previous training. Likewise, in terms of materials it was found that they are scarce in most of these schools. The study confirms that that there are local needs that have to be considered before accommodating any foreign model.

Putting educational contexts aside for a moment, there are also geographical conditions that in Europe favor and make it easy for Europeans to become plurilingual. European countries need to communicate on their borders with the other cultures that sometimes speak different languages. On the other hand, the countries that surround Colombia do not speak different languages. This means that Colombians' needs are not the same as Europeans'. In this sense the concept of mobility (CEF, 2001 p. 2) doesn't account for our socio-economical situation: first because for Colombians, it is not easy to go abroad and second because English would only be necessary for us if we traveled to an English speaking country.

Coming back to the linguistic affair, it is seen that some of the primary motivations for foreign languages learning in Colombia are based on the premise that a foreign language is prestigious ${ }^{13}$. This is due to the fact, that speaking foreign languages bring about expectations or represent benefits, essentially in three views: the academic, the economical and the cultural ${ }^{14}$. The academic view deals with the conception that languages are no more than a

13 Hohenthal (2004, citing Fishman and Agheyisi, 1970); Moreno 1998, and Romaine, 2000 talk about "language prestige", they describe it as the status and importance of a language in society and within an individual. These authors also assert that the prestige of a language builds a mentalist and behaviorist viewpoint that determine language attitudes. Attitudes involve favorable and unfavorable feelings or behaviors toward personal or social situations related to language interactions.

14 Related to this division, Ellis (1991) points out two kinds of motivations to language learning: integrative and instrumental. In the integrative motivation the apprentice aims at learning the language and the culture of the target language as a possible way to be able to become a member of the group. The instrumental motivation comes from the sense of achieving an academic or communicative success. An ideal learner under our perspective should integrate all kinds of motivations: integrative (socio-cultural), instrumental (academic) and economical since undertaking another language is a process that has to do with several dimensions that ought not to be isolated. 
subject matter or a component of the academic activity. The second has to do with the idea that by learning a language there are chances to have a better: income, job promotion or business progress. Culture as the third aspect, is considered as the means by which languages give access to socio-cultural aspects namely music, customs, sports, religion etc., of other cultures. Although the three views overlap, there is a higher emphasis on one of the three.

It seems to be that the academic view, is more evident than the economical and the cultural perspectives. The term academic, as it is posed here, suggests that language is a subject matter and is part of an educational curriculum at a school or university. For example, some language teachers and students at different educational levels think that a FL is just a class that allows learners to be promoted to another level or course, that is, it has only academic purposes. For this reason, the learning of a language is seen as a determined short term process that will finish with some institutional or national exams; which constitutes a very reductionist idea of what a language is or what it is for.

A possible way to overcome the academicist view, that in many cases governs the FL processes in this country, is by assuming a pluricultural sperspective. Nevertheless, there are certain situations that make this task difficult. One principal issue is that there is no official policy that requires total participation of the population in the learning of foreign languages as the Council of Europe proposes. This difference exemplifies the dissimilar contextual needs and policies of Europe and Colombia. A basic reason is that binational schools in Colombia provide a particular type of program referred as "elite bilingual education", which serves mainly children of upper class, professional parents (de Mejia, 2002; as cited by López and Sosa, 2004). Additionally, not everybody has the need to learn a foreign language because our social-political problems give priority to other issues such as violence, unemployment, and education among others. Consequently, some policymakers, teachers and learners still see a foreign language as just another subject matter to learn and not a means of communication and enrichment of their knowledge of the world.

\section{Cultural and academic issues}

One of the contradictions of the policies on foreign language education in our country is the fact that we are talking about bilingualism and thus disregarding our multicultural and multilingual nature. According to a study 
developed by the Departamento Nacional de Estadística (DANE) in 1993 and revised in 1997, in Colombia there are more than 701,860 aborigines grouped in 80 indigenous communities that speak around 64 languages and some 300 dialectal varieties (Fundacion Hemera, 2005).

These communities with perseverance have preserved their native languages which users of the dominant national language are not interested in learning. It seems that current language policies aim at achieving bilingual and bicultural learners, but they forget the multiculturalism and multilingualism that are the essence of our cultural heritage and identity. It is observed, paradoxically, that this multiculturalism and multilingualism is not only being jeopardized by a language like English but also the Spanish language.

As well as English language in many countries around the world, Spanish has reached a status of a prestigious language within most indigenous tribes in Colombia. Socio-cultural power and pressure attached to this dominant language has compelled indigenous speakers to adopt diverse language attitudes. Some of these language attitudes are associated to xenophobic feelings, practices that go against the maintenance of their native tongue, or ethnic immersion in the culture of the prestigious language, thus forgetting cultural heritage. But, not only linguistic issues are at the core of this phenomenon, there are political, economical and educational issues too.

Although the General Law of Education (1994) protects indigenous languages, it is well known that some indigenous communities are forgetting their cultures and native languages due to political, economical and educational interests. This happening shows that these communities are in a process of cultural and linguistic assimilation. The result is a subtractive phenomenon in which they will be forced to adopt the dominant culture as well as its language at the expense of their cultural inheritance. As a result, Fundación Hemera states:

"... the racial discrimination among Colombians has a concrete objective as well as another ideological and subjective one. The first is practiced by the state and the leading social classes when keeping black people and indigenous communities in territorial isolation, underdevelopment, inequality and exclusion... The second, when in the social conscience of Colombians remains the racial prejudice that humiliates their equality and human dignity..."15

15 Translation by the authors 
In Europe as well as in Colombia there is the tendency to talk about multiculturalism and multilingualism, as mentioned by the Ministry of Education, but there are some discrepancies:

- The phenomena of multiculturalism and multilingualism occur differently in both contexts. On the European continent there are different languages that co-exist in a country. Additionally, neighboring countries also speak different languages such as French, German, Dutch, etc. In Colombia, there are many indigenous languages which barely co-exist, and there is not such a linguistic variety since surrounding nations speak Spanish as well, except for Brazil.

- While Europe has already recognized its multiculturalism and multilingualism, it is moving towards pluriculturalism and plurilingualism. Colombians have not even acknowledged their multicultural and multilingual nature since the aforementioned minority groups are still disregarded or not totally taken into account.

- Europeans have proposed the CEF as a language program to safeguard their linguistic and cultural diversity whereas Colombia has not proposed much about foreign languages. Instead, there are projects that intend to adopt the CEF despite the differences mentioned.

Other aspects that need to be considered when implementing a model such as the CEF are the view of language, the learner, methodologies, strategies and materials that comprise the model. It is necessary to study in depth how these features match our circumstances or how we can adapt them as regards our own setting.

For instance, the CEF proposes a number of hours that a learner needs to achieve native-like proficiency. It asserts that this is attained after one thousand hours or more of independent work and exposure to the target language. As previously posed, our contextual characteristics (learner and teacher traits) and educational system are not ready yet for such a challenge. Looking at the number of hours of a foreign language class that a learner receives in Colombia, we conclude that a student receives more than nine hundred hours during his/ her schooling. Yet if his/her language proficiency is measured, it is seen that the apprentice still lacks a great deal to achieve native-like proficiency.

The CEF in agreement with the ALTE (Association of Language Testers in Europe) has determined the levels and scales of proficiency and the 
corresponding descriptors. Furthermore, these entities have set the number of hours needed to achieve each level. The scales and levels are the product of ongoing research in different European communities that are carried out by these two institutions. This issue raises the question of to what extents can a Colombian FL student be assessed or evaluated by using the criteria established by the CEF.

This section has reflected on some of the main implications of implementing the CEF in Colombia. It has considered this phenomenon from two perspectives, the socio-political and economical, as well as the cultural and academic dimensions. Next, in order to answer the second guiding question of this paper we must examine important points regarding what the academic community is likely to do as a way of building up new EFL agendas in Colombia.

\section{A course of action}

Some common questions that might raise when one thinks about education in Colombia are, what factors should be considered to set standards and who will be in charge of such responsibility? Given the nature and the complexity of what the educational affair involves; it is comprehensible that there is not a specific formula to answer the queries posed. Despite this fact, we would like to mention some general aspects which aim at shedding light on them.

Among the factors that are at the core of attention for developing a proposal for standards in this country, there is the fact of copying or adopting foreign models. The practice of copying or adopting foreign models as standards needs to be revised. People involved in education, the government, administrators and in general all the members of the academic community should be aware of the complexities of educational standardization. They should not forget that both research and policies in bilingual education are motivated by particular political and economical agendas (Romaine, 2001). As stated before in this document, the adoption or perhaps adaptation of foreign standards is an intricate process that has to consider the features of the context of implementation.

Consequently, proposals regarding education should be designed to set curricula that reflect, satisfy, and fulfill Colombian learners' needs. In other words, as stated by Zuñiga \& Bernal (2004), ..."a curriculum is the connection between the relationship with nature, the country, society, technology and 
ourselves as teachers. ${ }^{16}$ Research done by Peñafort (2002) illustrates how the construction of bilingual curricular proposals ought to obey these contextual features. One of the conclusions arising from the five research experiences mentioned by the author is the importance of avoiding the adaptation of imported bilingual models where the institutions are embedded.

It is important to highlight that the support of the government plays an important role if significant changes are to be made to overcome the limitations of the Colombian educational system. As an action to bridge the gap between public and private education, the government ought to improve, among others, aspects regarding budget -which serve to invest in research, logistics for schools, universities or other public educational institutions; more chances for students to study, and teachers' professional development. Additionally, policies about first language education and foreign language education, for the dominant language and the indigenous languages, have to be revised.

The position of the Colombian indigenous cultures and their languages should not be put aside in the development of standards for language teachinglearning, since they are part of our educational, cultural and linguistic context. The role of English and Spanish as prestigious languages in several Colombian domains especially within indigenous languages needs to be addressed. It is necessary to study in which ways English language is building language attitudes toward Spanish and indigenous languages, and in this order to analyze the consequences of the role of Spanish as a language of prestige with respect to the indigenous dialects.

These facts must be kept in mind when dealing with bilingual, multilingual and plurilingual education. Therefore, educational policies need to nurture the development of the L1 of all linguistic communities in our country, as a manner of bolstering identity. It is worth noting according to Rico, (2004), that: “... it is fundamental to recognize the importance and status of the mother tongue as an enabling element to the encounter and convergence of other languages" (p.170). ${ }^{17}$

16 Translation by the authors

17 Pertinence, in this context, is understood as the appropriateness of the actions taken in order to develop a coherent proposal of standards. This distinction is made because it may happen that proposals achieve coherency but they are not pertinent or viceversa. 
Research suggests that it is advisable to first strengthen educational policies regarding the mother tongue so as to be able to undertake the learning of a foreign language. (Ramirez, et al. 1991; as cited by Torres-Guzman, 2002; Freeman, R (1995); Romain, 2001, de Mejia, 2002; Krashen, 1987; Cummins, 1984; Hakuta y Díaz 1984 1986; and Oller 1981; as cited by the MEN, 1999). Furthermore Clavijo (conference on bilingualism in Argentina, 2004) states that it is essential to work on an educational model that enhances literacy processes in the mother tongue as well as the target language, and towards models that promote bilingualism and multilingualism in accordance with our context.

Now, if we ask who has to lead and support the process of standards construction for FL in our country, there is only one answer: the academic community. We advocate a broader participation of all the academic community, which has the responsibility to develop and validate language teaching-learning standards to cope with the dynamics of the current educational system in Colombia. Thus, policy makers, teachers, students, parents and school administrators should be leaders and active participants as observers and members of such academic community.

In this sense, the academic community ought to establish what the national standards should include for their further development. It is necessary to depart from principles of pertinence and coherence ${ }^{18}$. The development of standards implies the making of pertinent decisions in order to construct standards that coherently account for the features of the context we are embedded in. These decisions have to do with the design of a curriculum. According to Dubin E Olshtain (1987) a curriculum entails the formulation of general goals by indicating an educational-cultural philosophy which applies across subjects together with a theoretical orientation to language and language learning. On the whole, a curriculum deals with policy decisions and it combines educationalcultural goals with language goals.

A curriculum focuses on three major views: a view on the nature of language, a view on the nature of language learning and an educationalcultural view (Dubin E Olshtain, 1987, p.35). A proposal on FL standards should evidence the pertinence and coherence in the articulation of these three

18 Translation by the authors 
dimensions of a curriculum. That is to say, to establish how these orientations fit and match, in this case, the Colombian ethnic, political, economical, cultural and social reality. Then, it is essential to pay attention to the correspondence among what we believe the nature of language is -a way to communicate, a set of grammar rules; the way the language is learned -a stimulus-response activity, a cognitive activity; and the educational viewpoint we hold -a behaviorist orientation, a humanistic orientation.

The process of designing a proposal for standards starts with the consideration of the pertinence and coherence among the components of the curriculum. The next step is the arrangement of more specific standards throughout a syllabus proposal. A syllabus is the translation of the philosophical and theoretical views about language and learning into operational goals (Dubin E Olshtain, 1987). Under these principles, a syllabus has to pose standards that correspond to attainable goals based on a student population analysis. Likewise, it must depict the criteria to decide on what is to be taught -elements or themes- and the order or sequence of their presentation. It also describes methods, techniques, materials, evaluation systems, and roles of teachers and learners in the learning process.

Standards, as it has been shown, engage a coherent articulation of various dimensions namely, the components of a curriculum and the aspects that characterize a syllabus. It means that standards do not only cope with subject matter content, its goals and outcomes; standards embrace broader dimensions which integrate cultural (L1 vs. FL, indigenous languages), societal (language prestige, status), and individual (interests, motivations, personal goals) domains. It is still a challenge, for all who are involved in education, to put together all the components that standards should include. Most of this responsibility lies on teachers and their expertise.

Thus, in order to reverse the perpetuation of the status quo of our educational reality, the academic community, but in particular teachers play a relevant role. Educational proposals should depart from the experiences of teaching practice. Teachers need to assume a teacher-researcher role and systematize their teaching experiences. This will allow them to use and build up theory and, as a result, to develop educative proposals such as standards.

Theory has to interact in a dialectical way with practice. De Beaugrande (2002) proposes a dialectical cycle in which practice is conducted by theory and 
theory has to be conducted by practice; theory leads and explains practice, and practice specifies and implements theory ${ }^{19}$. To put it in another way, teachers have to remain true to their praxis (Freire, 1970), that is to say, they need to make use and develop theory, reflect and take action as a manner to shape new curricula based upon their daily experience and the comprehension of their local realities. In short, standards should be born from the practice of teachers and the involvement of the other participants of the academic community.

\section{Conclusion}

This article is a discussion that attempts to reflect on some implications of the implementation of the CEF in Colombia given the socio-cultural, political and economical traits of our country as well as education system. The writers acknowledge the value and contribution of the CEF in foreign language teaching-learning. Nevertheless, we point out the several issues to bear in mind along with the possible repercussions of adoption and the way a model such as this one is interpreted and implemented in a different context. We agree that "Educational policies should not be implemented blindly without a careful analysis of our contexts and without knowing the real needs of our teachers and students" (Cadavid, McNulty \& Quinchía, 2004; p.44).

Overall, we assert that standardization is not negative in the sense that it implies taking action in order to improve or gain better quality. It aims at improving competitiveness at an international level and has an impact on any system as it attempts to compare and reevaluate current practices. All actors involved in foreign language teaching-learning processes need to assume a critical stance toward the concept of standards, which must not be seen as stylish products coming from abroad. On the contrary, international standards in education should inform us what our position in the world is. Therefore, we can change our perspective while considering our background in order to meet local but at the same time wider requirements of a globalized world.

19 Translation by the authors 


\section{References}

Association of Language Testers in Europe (ALTE). (2004). The can-do statements. Retrieved August 5, 2004 from www.alte.org.

Association of Language Testers in Europe (ALTE), (2004). Quality assurance. Retrieved August 5, 2004 from www.alte.org.

Cadavid, I. McNulty M. \& Quinchía, D. (2004). Elementary English Language Instruction: Colombian Teachers' Classroom Practices. Profile, 5, 37-55.

Casassus, J. (2004). Documentos: Laboratorio Latinoamericano de Evaluación de la calidad de la educación. Estándares en educación 3: conceptos fundamentales. UNESCO. Retrieved June 15, 2004 from http://llece.unesco.cl/medios/pdf/espanol/libro_1.pdf

Clavijo, A. (2004). Perspectivas críticas del proyecto Bogotá y Cundinamarca Bilingüe. Buenos Aires. Argentina. Primer congreso sobre Bilingüismo y Educación Bilingüe, abril. Universidad Distrital Francisco José de Caldas.

Council of Europe (2001) Common European Framework of References for Languages Learning Teaching, Assessment (2001). Cambridge University Press.

De Beaugrande, P. (2002). La agenda del ecologismo para el estudio del texto y el discurso. In Análisis del discurso en las ciencias sociales, la cultura y el territorio. Bogotá: Instituto Caro y Cuervo.

Dubin, F. \& Olshtain, E. (1994) Course design. Cambridge: Cambridge University Press.

Ellis, R. (1991). Understanding Second Language Acquisition. Oxford: Oxford University Press.

Freeman, R. (1998) y Dubin \& Olshtain (1987). Bilingual education and social change. Great Britain: Multilingual Matters, Ltda.

Freire, P. (1970). Pedagogy of the Oppressed. New York: Seabury.

Fundacion Hemera. (2005). Etnias de Colombia. Retrieved January 9, 2005 from http://www. etniasdecolombia.org/grupos_pueblos.asp)

Gonzales, A. \& Quinchía, D. (2003). Tomorrow's EFL Teacher Educators. Colombian Applied Linguistics Journal, 5, 86-104.

Hammers, J. \& Blanc, M. (2000). Bilinguality and Bilingualism. Cambridge: University Press.

Harding, E. \& Riley, P. (1994). The Bilingual Family: A Handbook for Parents. Cambridge: Cambridge University Press.

Hohenthal, A. (2005). Measurement Techniques. What is a Language Attitude? Retrieved July 17, 2005 from http://www.postcolonialweb.org/india/hohenthal/bibliography.html

Krashen, S. (1987). Applications of psycholinguistic research to the classroom. Long M., and Richards, J. (Eds). Methodology in TESOL: A Book of Readings. New York: Newbury House Publishers. 
López, A. \& Sosa, Y. (2004). Developing emergent bilateracy: guiding principles for instruction. Colombian Applied Linguistics Journal, 6, 7-22.

Ministerio de Educación Nacional de Colombia (1994). Ley General de Educación. Santafé de Bogotá: MEN.

Ministerio de Educación Nacional de Colombia (1999). Lineamientos curriculares-Idiomas extranjeros. Santafé de Bogotá: MEN.

Moreno, F. (1998). Principios de sociolingüística y sociología del lenguaje. Editorial Ariel, S.A.: Barcelona.

OTI organización internacional del trabajo (2004). La gestión de la calidad en la formación profesional. El uso de estándares y sus diferentes aplicaciones. Retrieved July 26, 2004 from http://www.ilo.org/public/spanish/region/ampro/cinterfor/rct/36rct/doc ref/doc2/ii.htm

Peñafort, C. (2002) Experiencia en la construcción de propuestas curriculares bilingües para colegios monolingües de la ciudad de Cali. In De Mejía, A \& Nieves, R. (Eds). Nuevos caminos en educación bilingüe en Colombia. Cali: Universidad del Valle.

Rico, C. (2004). Reflexiones del quehacer evaluativo del ICFES en los últimos años: Área de Idiomas. In Evaluación por Competencias. Lenguaje Idioma Extranjero: Inglés. Bogota: ICFES-Magisterio.

Roberts, C. (1995). Bilingual education program models: a framework for understanding. The Bilingual Research Journal, 19, (3\&4), 369-378. Retrieved January 2, 2005 from www. ncela.gwu.edu/pubs/nabe/brj/v19/19_34_roberts.pdf

Romain, S. (2001). Bilingualism. Merton College, University of Oxford.

Torres-Guzman, M. (2002). Dual-language program: key features and results. Directions in Language Education,14. National Clearinghouse for Bilingual Education. Retrieved January 2, 2004 from http://www.ncbe.gwu.edu.

Zuñiga, G. \& Bernal, S. (2004). Estándares Básicos de Calidad en Inglés. Neiva, Col. USCO. Unpublished.

Webster's New World College Dictionary. (3rd Ed), (1997). USA: McMillan.

\section{THE AUTHORS}

*Jair Ayala Zárate is a candidate to the Masters in Applied Linguistics. He is currently a full time teacher at Universidad Pedagógica Nacional. Additionaly he works at Universidad La Salle and is an ESOL international examiner for Cambridge.E-mail: jairwoodstock@yahoo.es

** José Aldemar Álvarez V. holds a Master's degree in Applied Linguistics and is a first-year student at the Master in Hispanic Linguistics at the Instituto Caro y Cuervo. He works at Universidad Pedagógica Nacional as a part time teacher and is an ESOL international examiner for Cambridge. E-mail: josea_edu@yahoo.com 